\title{
PUBLICAC̣ÃO DE PERIÓDICOS NACIONAIS DE CIÊNCIA EM PAÍSES EMERGENTES
}

Rogerio Meneghini*

A motivação para produzir periódicos científicos em países emergentes difere daquela de países desenvolvidos. Nestes, a força propulsora é primordialmente comercial, embora o interesse científico esteja necessariamente presente. Estes periódicos almejam publicar resultados científicos em diferentes áreas do conhecimento, com uma grande variedade de abordagens, focando o caráter inovador, o rigor metodológico e a relevância dos resultados. Em países emergentes, a produção de periódicos não tem sentido comercial, prestando-se mais a dar vazão à informação científica gerada e que não escoa facilmente para os periódicos internacionais por razões várias. Ademais, ela é significativamente dependente de recursos públicos.

É interessante que países desenvolvidos não competem por publicar mais periódicos nacionais. De fato, países com produção científica similar podem diferir muito em produção de periódicos. A título de exemplo, se tomarmos a base Web of Science-Thomson Reuter, a mais prestigiosa mundialmente, com cerca de 11 mil periódicos indexados, os títulos ali publicados pela Holanda, pela Suíça e pela Suécia, em 2010, foram de 847, 202 e 30, respectivamente. A Holanda é uma meca tradicional de publishers de periódicos. Por outro lado, o número de artigos publicados em todos os periódicos, dessa mesma base, por esses países (uma medida da produtividade científica) não difere significativamente.

* Doutor em Bioquímica pela Universidade de São Paulo (USP); Coordenador Científico do Programa SciELO (Scientific Electronic Library Online). E-mail: rogerio.meneghini@scielo.org 
Neste contexto, num país desenvolvido, em vez do número de periódicos nacionais, o indicador mais próximo do prestígio científico é o número de seus cientistas em posições editoriais estratégicas (gatekeepers), principalmente nos periódicos mais influentes, independentemente da nacionalidade destes (BRAUN; DIOSPATONYI, 2005). Esses cientistas são quem vai coordenar o progresso do movimento científico. Participar dessa orquestra é meritório e envolve uma responsabilidade ímpar, a de desenhar o contorno da ciência contemporânea.

Para dar uma ideia da representação nacional nessa orquestra, retomando a Holanda, a Suíça e a Suécia, os números de gatekeepers de 220 periódicos selecionados de alto prestígio foram de 235, 256 e 160, respectivamente (BRAUN; DIOSPATONYI, 2005). Isto é, valores próximos entre si, em correspondência à proximidade da produtividade científica desses países. Em contrapartida, a representação de gatekeepers do Brasil, da Coréia do Sul e da Rússia, países de produtividades científicas próximas à da Holanda, da Suíça e da Suécia, foi de 28, 29 e 55, respectivamente. Portanto, a sub-representação de países emergentes no time responsável pela definição do curso da ciência moderna é patente. Essa tendência se repete para outros conjuntos de países desenvolvidos e emergentes.

A decisão de países emergentes em adotar a estratégia de aumentar a publicação de periódicos nacionais tem a ver com outro fator: a dificuldade em superar barreiras para publicação em periódicos internacionais. Essa dificuldade tem sido largamente discutida com respeito às suas causas e, certamente, algumas delas são facilmente identificáveis: a qualidade média inferior da ciência produzida em países emergentes, proficiência pobre no inglês escrito, a língua franca da ciência moderna (MENEGHINI; PACKER, 2007) e, embora não como causa maior, como alguns gostam de alardear, preconceito dos editores internacionais ao examinar artigos de países emergentes (MENEGHINI; PACKER; NASSI-CALO, 2008). Como consequência, a forte atividade científica em países emergentes, nas últimas três décadas, forçou-os a lançar um grande número de periódicos para dar vazão a essa massa de resultados por meio de publicações.

Em princípio, há a intenção de manter esses periódicos sob as regras rígidas e centenárias de avaliação por pares. No entanto, esse processo não tem alcançado resultados satisfatórios. Uma razão relevante é que a prática competente de avaliação por pares é fortemente conectada 
à competência científica e à experiência dos atores envolvidos no próprio processo de avaliação, rarefeita na comunidade. Ademais, uma tendência à leniência parece acompanhar a prática, talvez devido à percepção de que um procedimento mais rigoroso seria contrário à intenção precípua de trazer essa massa de informação e resultados científicos ao âmbito geral (MENEGHINI, 2012).

\section{As duas rotas de publicação}

Neste ponto, deve-se considerar que, em países emergentes, tem havido crescimento paralelo de duas tendências de comunicação em ciência, uma centrada na publicação em periódicos internacionais, a rota seletiva, e outra inclinada para a escolha de periódicos nacionais para a publicação dos artigos, a rota regional. Os pesquisadores não estão rigidamente ligados a uma ou outra rota, mas pode-se notar um contorno nítido dessas duas comunidades, muito influenciadas pelas áreas de atividade de seus participantes. Muito comum entre os seletivos é um desdém pela publicação em periódicos nacionais, olhada como um caminho para evitar o esforço e a competência requeridos para publicar internacionalmente. Por outro lado, os regionais entendem seus esforços como uma forma importante de fluir a informação gerada pela comunidade científica nacional, que, de outra forma, permaneceria represada e inútil.

A forma como o governo enxerga essas rotas divergentes varia entre os países emergentes. No entanto, é importante mencionar que, em geral, os participantes do time seletivo têm mais prestígio e suas vozes tendem a ser mais ouvidas pelas autoridades de política científica. Dado o fato de que os recursos para produzir periódicos nacionais vêm diretamente do governo, pode-se antecipar que os editores passam por agruras para manter seus orçamentos.

\section{0 processo cíclico da fabricação da ciência}

O processo de fazer ciência é inerentemente cíclico e envolve várias etapas, como mostrado na Figura 1. Os cientistas constituem o elemento mais importante do ciclo; eles são tanto a mola propulsora quanto 
o resultado, no ciclo que assegura a continuidade e o fortalecimento do processo. A intenção do esquema é apenas mostrar os passos mais importantes da produção científica, cada um dominado, em diferente extensão, pelos países emergentes. No entanto, um problema comum a todos eles ocorre quando se alcança o ponto de publicação: qual rota seguir, a seletiva ou a regional? A bifurcação é emblemática porque consequências distintas são encontradas em cada uma das rotas. Por um lado, a rota seletiva, trilhada pelos pesquisadores de maior prestígio, pode levá-los a uma maior visibilidade internacional, mormente quando há publicação profícua nos periódicos de mais renome. Porém, em países emergentes, isso se reflete fracamente na participação desses cientistas nos corpos editoriais de periódicos internacionais, isto é, na pirâmide de poder científico, como já exemplificado.

Parece que há outras credenciais que pesam nesse acesso, possivelmente ligadas a outras aptidões: domínio amplo do inglês (científico e social) e autoridade na competência de avaliação de ciência de ponta, são dois exemplos que, compreensivelmente, pesam contra países emergentes. A consequente sub-representação na pirâmide certamente causa problemas para esses países: a falta de oportunidade de se tornarem familiarizados com a dinâmica de peer-review em ciência de primeira classe e com os procedimentos de administração de periódicos de alta qualidade. À primeira vista, parece que, num curto horizonte de tempo, será difícil mudar esse panorama.

Parte dos editores e usuários da rota regional aspiram a que esses periódicos se tornem mais visíveis e reconhecidos como fonte de informação valorizada, e não apenas um instrumento de vazão ao público de um conhecimento acumulado.

A representação cíclica da fabricação da ciência é apropriada por outra razão importante: mostra que a publicação não é o ponto final de uma atividade científica, como às vezes se descreve. Ela realimenta o ciclo, com novos conhecimentos e proposições. Portanto, deixar de publicar, por qualquer razão, é romper um elo do processo e, consequentemente, interromper um avanço da área de pesquisa em que o ciclo se insere. 


\section{FIGURA 1}

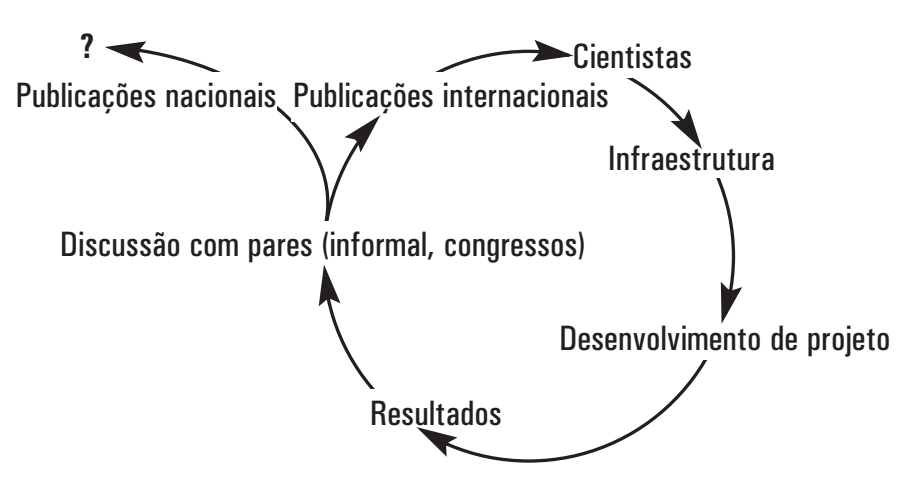

\section{Periódicos nacionais: quebrando o ciclo vicioso}

Surpreendentemente, parece estar na rota regional da publicação a oportunidade de mudar o cenário e quebrar o ciclo vicioso de publicar ciência. De fato, a rota seletiva lança o cientista de países emergentes num mundo mais virtuoso de ciência, mas não confere a ele instrumentos para operar de forma mais incisiva no processo de avaliação científica, em posição editorial de periódicos internacionais prestigiosos.

Por outro lado, a rota regional apresenta fragilidade, fundamentalmente no processo de peer-review, por fatores múltiplos: (I) treinamento incipiente em avaliação objetiva pelos pesquisadores brasileiros; (II) leniência e má vontade, por parte dos pesquisadores da rota seletiva, em avaliar artigos dos pesquisadores da rota regional. Como se mencionou, as razões residem na forma desdenhosa como os primeiros encaram a publicação nacional. Fica-se numa situação intricada: de um lado, a inépcia em avaliar e, do outro, a desmotivação para fazê-lo. A mola propulsora do aprimoramento de periódicos resulta fraca, os periódicos não progridem e a ciência, que, no processo cíclico, depende de boas publicações, esbarra nesse entrave.

Porém, se não temos muito espaço para influenciar nos procedimentos de avaliação internacional, não temos impedimentos insuperáveis para atuar e modificar os procedimentos de avaliação regional. A chave é internacionalizá-los e profissionalizá-los. As duas ações são interdependentes. A grande maioria dos periódicos nacionais está sob o comando de sociedades e instituições. A estrutura editorial é, em geral, blindada, endogênica e amadorística. O Programa SciELO (Scientific Electronic Library Online) teve papel importante para dar um passo à frente, ao se tornar um 
referencial de qualidade para indexação na sua base. No momento da indexação, pode fazer certas exigências de mudanças que, no contexto editorial, são restritas a uma flexibilização da endogenia regional e institucional e a uma internacionalização do corpo editorial, a qual acabou, no geral, se mostrando perfunctória. A fragilidade do sistema é que a administração de cada um desses periódicos é feita pela sua sociedade ou pela sua instituição específica, com pouco preparo profissional e com recursos parcos.

O turning point do processo exigiria que os periódicos passassem a ter ligação mais estreita com um empreendimento editorial qualificado. O SciELO está apto a assumir essa função, mas editoras internacionais têm também qualificações para tal. Fundamentalmente, o empreendimento editorial deveria ter voz ativa na montagem do corpo editorial, na escolha de assessores ad hoc e no acompanhamento da performance do periódico, atento para necessidades de mudanças. Deveria ter um núcleo de 2-3 editores-chefes por periódico, com um ao menos internacional e com experiência comprovada, trabalhando em conjunto e com salários compatíveis. Suas competências no domínio do inglês, da ciência pertinente ao periódico e suas influências na comunidade para convocar assessores ad hoc que avaliassem os artigos com presteza e objetividade catalisariam a melhoria rápida dos periódicos e de seus indicadores de qualidade. Mais ainda, eles teriam papel educativo, introduzindo um ambiente de aprendizagem na comunidade nacional, levando-a a assimilar a experiência editorial e passando a se mesclar mais naturalmente à comunidade de editoração científica internacional. Seria fundir as rotas regional e seletiva numa única rota internacional de comunicação científica.

No caso brasileiro, o modelo de acesso aberto (artigos acessíveis livremente na internet) prevaleceu na quase totalidade dos periódicos, uma singularidade mundial. Para que ele se sustente com os aperfeiçoamentos aqui preconizados, deverá ser acompanhado por um modelo financeiro de sustentabilidade. A forma ideal é o autor pagar, com recursos de seus projetos, o acesso aberto de seu artigo (algo em torno de 2 mil reais). Esse modelo proveria financiamento contínuo dos periódicos e estabeleceria um processo mais dinâmico de escolha pelos autores de seus periódicos de preferência. Este, em si, se constituiria num procedimento de avaliação dos periódicos pela comunidade, certamente mais eficiente do que o que opera no Brasil: as agências de fomento cumprindo (mal) essa função. 


\section{Referências}

BRAUN. Tibor; DIOSPATONYI, Ildiko. The counting of core journals gatekeepers as science indicators really counts. The scientific scope of action and strength of nations. Scientometrics, v. 62, n. 3, p. 297-319, 2005.

MENEGHINI, Rogerio; PACKER, Abel L. Is there science beyond English? EMBO reports, v. 8, n. 2, p. 112-116, 2007.

MENEGHINI, Rogerio; PACKER, Abel L.; NASSI-CALO, Lilian. Articles by Latin American Authors in Prestigious Journals Have Fewer Citations. PLoS ONE, v. 3, n. 3, e3804, 2008.

MENEGHINI, Rogerio. Emerging journals. The benefits of and challenges for publishing scientific journals in and by emerging countries. EMBO reports, v. 13, n. 2, p. 106-108, 2012.

Recebimento: 01/05/2012

Aprovação: 25/07/12

Contato:
SciELO/Fundação de Apoio à Universidade Federal de São Paulo/UNIFESP
Rua Dr. Diogo de Faria, 1087, $8^{\circ}$ andar, cj. 801
Vila Clementino
CEP 04037-003
São Paulo, SP
Brasil


